EPJ Web of Conferences 21, 08010 (2012)

DOI: $10.1051 /$ epjconf/20122108010

(C) Owned by the authors, published by EDP Sciences, 2012

\title{
Minimization of actinide waste by multi-recycling of thoriated fuels in the EPR reactor
}

\author{
S.J. Rose ${ }^{1, a}$, J.N. Wilson ${ }^{2}$, N. Capellan ${ }^{2}$, S. David ${ }^{2}$, P.Guillemin ${ }^{3}$, E. Ivanov ${ }^{4}$, O. Méplan ${ }^{3}$, A. Nuttin
} and S. Siem ${ }^{1}$

${ }^{1}$ University of Oslo, Department of Physics, P.O. Box 1048, Blindern 0316 Oslo, Norway

${ }^{2}$ Institut de Physique Nucléaire d'Orsay, Bât 100, 15 rue G. Clémenceau, 91406 Orsay cedex, France

${ }^{3}$ Laboratoire de Physique Subatomique et Cosmologie, 53 rue des Martyrs, 38026 Grenoble, France

${ }^{4}$ Institut de Radioprotection et de Sûreté Nucléaire 31, ave. de la Division Leclerc, 92260 Fontenayaux-Roses, France

\begin{abstract}
The multi-recycling of innovative uranium/thorium oxide fuels for use in the European Pressurized water Reactor (EPR) has been investigated. If increasing quantities of ${ }^{238} \mathrm{U}$, the fertile isotope in standard $\mathrm{UQ}_{2}$ fuel, are replaced by ${ }^{232} \mathrm{Th}$, then a greater yield of new fissile material $\left({ }^{233} \mathrm{U}\right)$ is produced during the cycle than would otherwise be the case. This leads to economies of natural uranium of around $45 \%$ if the uranium in the spent fuel is multi-recycled. In addition we show that minor actinide and plutonium waste inventories are reduced and hence waste radio-toxicities and decay heats are up to a factor of 20 lower after $10^{3}$ years. Two innovative fuel types named $\mathrm{S} 90$ and $\mathrm{S} 20, \mathrm{ThO}_{2}$ mixed with $90 \%$ and $20 \%$ enriched $\mathrm{UO}_{2}$ respectively, are compared as an alternative to standard uranium oxide (UOX) and uranium/plutonium mixed oxide (MOX) fuels at the longest EPR fuel discharge burn-ups of $65 \mathrm{GWd} / \mathrm{t}$. Fissile and waste inventories are examined, waste radio-toxicities and decay heats are extracted and safety feedback coefficients are calculated.
\end{abstract}

\section{Introduction}

Thorium is a fertile material that can easily be transformed into fissile ${ }^{233} \mathrm{U}$ by thermal neutron capture. ${ }^{233} \mathrm{U}$ does not exist in nature but is an excellent fissile material which has a higher $\eta(\sim 2.3)$, the number of neutrons emitted per neutron absorbed, than the analogous fissile plutonium isotopes ${ }^{239,}{ }^{241} \mathrm{Pu}(\sim 1.7, \sim 2.1)$ from the U/Pu cycle. This implies that the yield of new fissile material in fuels containing fertile ${ }^{232} \mathrm{Th}$ will always be greater than for those containing fertile ${ }^{238} \mathrm{U}$, assuming a thermal neutron spectrum. Furthermore, the neutron capture/fission ratio of ${ }^{233} U(\sim 0.11)$ is lower than that of ${ }^{239} \mathrm{Pu}(\sim 0.55)$ and five successive neutron captures on fertile ${ }^{232} \mathrm{Th}$ are required to produce a trans-uranium element (TRU), while only one is necessary for fertile ${ }^{238} \mathrm{U}$. Therefore, production rates for the TRU's, the major long-lived nuclear waste components will be much lower if ${ }^{238} \mathrm{U}$ is replaced with ${ }^{232} \mathrm{Th}$.

\footnotetext{
a e-mail : sunniva.rose@fys.uio.no
}

This is an Open Access article distributed under the terms of the Creative Commons Attribution-Noncommercial License 3.0, which permits unrestricted use, distribution, and reproduction in any noncommercial medium, provided the original work is properly cited. 
We focus here on the EPR reactor and examine the consequences of removing significant quantities of fertile ${ }^{238} \mathrm{U}$ from conventional UOX fuel and replacing it with fertile ${ }^{232} \mathrm{Th}$ at the longest discharge burn-ups. This is achieved by blending thorium with uranium enriched to higher content of fissile ${ }^{235} \mathrm{U}$ than the typical 4\% needed for PWRs. We examine two new types of innovative fuel for the EPR, S20, a mixture of $20 \%$ enriched $\mathrm{UO}_{2}$ and $\mathrm{ThO}_{2}$, and $\mathrm{S} 90$, a mixture of $90 \%$ enriched $\mathrm{UO}_{2}$ and $\mathrm{ThO}_{2}$, and compare with conventional UOX fuel and MOX fuel fabricated from the plutonium recovered in spent UOX reprocessing.

The EPR is a Generation III + PWR concept, developed by Framatome and currently marketed by Areva. It is an evolutionary design rather than revolutionary and based on proven pressurized water technology, which is currently the most widely used worldwide. The EPR may use all different types of fuel currently burned in PWRs, and unlike older PWR designs, the EPR can be loaded entirely with MOX fuel. Due to this flexibility it could also in principle employ full core loading of $\mathrm{UO} 2 / \mathrm{ThO} 2$ fuels since the effective delayed neutron fractions of ${ }^{239} \mathrm{Pu}$ and ${ }^{233} \mathrm{U}$ are similar at 210 pcm and $261 \mathrm{pcm}$ respectively.

In theory, light water reactors (LWRs) with a thermal neutron spectrum using ${ }^{233} \mathrm{U} /{ }^{232} \mathrm{Th}$ fuels can breed self-sustaining amounts of new fissile material since 2.3 neutrons are available per neutron absorbed, and indeed breeding was proven in the Shippingport Light Water Breeder Reactor [1]. However, for a light water power reactor with realistically long cycle lengths there will be significant losses of neutrons to captures on the hydrogen in the water coolant, the fission products, the control poisons, the ${ }^{233} \mathrm{~Pa}$ intermediate thorium cycle nucleus and the structural materials, and thus the breeding ratio will be less than unity and breeding will be impossible. For breeding ratios of less than one, the thorium cycle will not be self-sustaining and the reactor will be dependent on a supply of some fissile material from the uranium cycle - either new fissile ${ }^{235} \mathrm{U}$ or ${ }^{239,241} \mathrm{Pu}$.

Concepts dedicated exclusively as thorium cycle breeder reactors have been suggested, e.g. the Thorium Molten Salt Reactor [2] and the use of thorium in sodium critical reactors [3], or in subcritical accelerator driven systems [4-6]. However, these technologies are very different from current power reactor designs and cannot use existing cycle infrastructure. A large amount of research and development is needed for these systems and thus commercial power production could be decades into the future. Since LWRs comprise around $80 \%$ of the world fleet of operating plants, the fastest way to explore the potential of thorium is through the use of innovative solid fuels in the existing infrastructure of operating plants.

The once through cycle (OTC) is the cheapest fuel cycle in the short term. However, the potential energy content of the residual fissile and fertile isotopes is lost, and the OTC also gives the largest possible volume of high-level waste. The potential energy content of the spent fuel provides an incentive to recover the fissile isotopes. Fuel recycling also reduces the mass of high-level waste and the time of high radio-toxicity of waste, thus reducing the requirements for both the number of repositories and the duration of geological storage. The goal of the present work is to examine thoriated fuels as an alternative to present MOX recycled fuels that should provide greater economy of uranium resources and lower waste inventories.

\section{EPR simulations with the MURE code}

An EPR assembly based on a $17 \times 17$ lattice was modeled using MURE (MCNP Utilities for Reactor Evolution), based on the Monte-Carlo neutron transport code MCNP5 [7]. MURE is a precision research code that has been developed jointly at the Institut de Physique Nucléaire d'Orsay (IPNO) and the Laboratoire de Physique Subatomique et Cosmologie (LPSC) of Grenoble [8]. MURE performs calculations of the time-evolution of reactor fuels with full 3D geometry. Consecutive MCNP calculations are performed to determine reaction rates and deduce core material evolution over time at a constant reactor power by solving the set of coupled differential equations for the production and destruction of isotopes. 
The EPR simulations presented in here are based on a single, homogeneous, core-equivalent assembly placed as an infinite lattice in the radial direction, but with axial leaks permitted. This assembly consists of 265 fuel pins of $0.475 \mathrm{~cm}$ outer radius with a M5 Zircaloy cladding of $0.57 \mathrm{~mm}$ thickness, and 24 guide tubes of radius $0.616 \mathrm{~cm}$ for insertion of control rods (see Figure 1). The fuel pins have homogeneous mixtures of $\mathrm{UO}_{2}$ and $\mathrm{ThO}_{2}$.

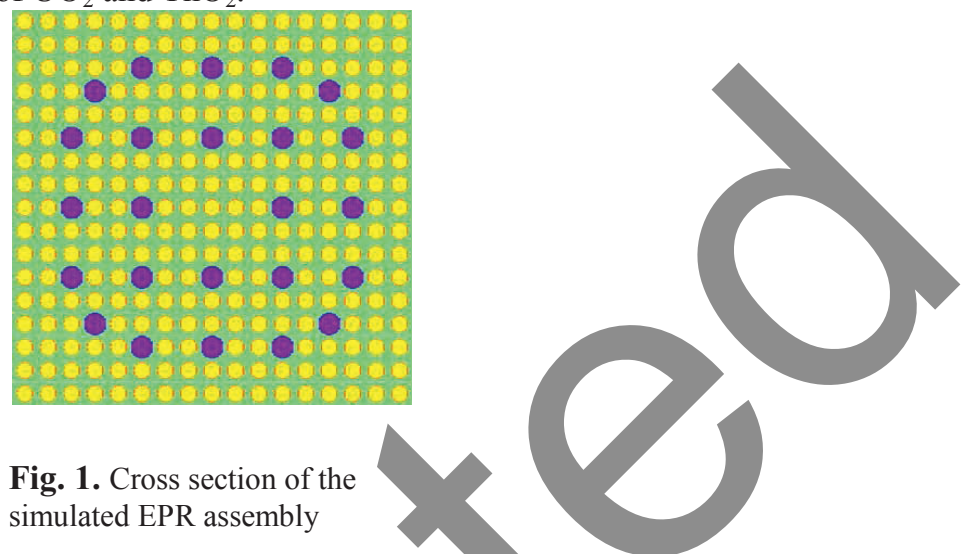

For any proposed innovative fuel types to be economically viable they must be able to compete with UOX fuels at the longest burn-ups, therefore only realistically long discharge burn-ups were studied. The EPR is designed to achieve long burn-ups of $70 \mathrm{GWd} / \mathrm{t}$, which is longer than current PWR's (typically 50-55 GWd/t). Therefore, for the present studies discharge burn-ups of $65 \mathrm{GWd} / \mathrm{t}$ were simulated.

To compensate the excess reactivity present after reloading points in the cycle, sufficient quantities of boric acid were added to the water coolant in the assembly. A fuel management scheme based on the use of three batches per cycle was used as is standard for operation of current PWR's. Simulation of the full cycle required around 70 consecutive MCNP calculations. The burn-up step lengths were chosen as $5 \mathrm{~h}, 21 \mathrm{~h}, 3$ days, 9 days and then repeated steps of 28 days to allow more frequent calculation of the fuel composition after startup where isotope concentrations are changing the most rapidly.

Initial uranium/thorium molar proportions for the fuels were found from fits to proportion vs maximum cycle length curves obtained from several fuel burn-up calculations at varying initial concentrations. The plutonium vector of the MOX fuel is taken to be the plutonium vector at discharge from the UOX fuel (containing 67\% fissile material) minus the losses of ${ }^{241} \mathrm{Pu}$, some of which decays to ${ }^{241}$ Am during the 5 year cooling period.

The UOX, S20 and S90 fuel types contain similar quantities of initial fissile ${ }^{235} \mathrm{U}$, although the thorium content varies considerably. The S20 and S90 fuels initially require more separative work units (SWU) and slightly more natural uranium, but this initial investment is repaid after the fuel is reprocessed, where the spent fuel will have a much higher recoverable fissile content. After discharge, the spent fuel was allowed to cool for 5 years before reprocessing and fabrication of new fuel. For the S20 and S90 multi-recycled fuels, the new fuel contains the uranium recovered from reprocessing the spent fuel and some fresh enriched uranium to compensate for the loss of fissile material during the irradiation. The recycled uranium will contain not only ${ }^{235} \mathrm{U}$ and ${ }^{238} \mathrm{U}$, but also all other long-lived uranium isotopes: ${ }^{232} \mathrm{U},{ }^{233} \mathrm{U},{ }^{234} \mathrm{U}$ and ${ }^{236} \mathrm{U}$. Due to the activity of the fuel, remote control of the operations is necessary, since the reprocessed uranium is made difficult to handle by the decay of ${ }^{232} \mathrm{U}(\mathrm{t} 1 / 2=69$ years $)$, which emits a high-energy $(2.6 \mathrm{MeV})$ gamma ray at the end of its decay chain. ${ }^{232} U$ is produced in small quantities in thorium-based fuels by ${ }^{233} U(n, 2 n) \rightarrow{ }^{232} U$, or ${ }^{232} \mathrm{Th}(\mathrm{n}, 2 \mathrm{n}) \rightarrow{ }^{231} \mathrm{Th}(\beta-) \rightarrow{ }^{231} \mathrm{~Pa}(\mathrm{n}, \gamma) \rightarrow{ }^{232} \mathrm{U}$. 
Figure 2 shows a schematic diagram of the multi-recycling of the thoriated fuels. $\mathrm{UO}_{2}$, enriched at either $20 \%$ or $90 \%{ }^{235} \mathrm{U}$, is mixed with $\mathrm{ThO}_{2}$ for fuel fabrication. The waste stream contains the TRUs along with the fission products (FP). The spent fuel is reprocessed and the recovered uranium and thorium are used to fabricate new fuel. It is assumed that the recovery process is not $100 \%$ efficient and there are reprocessing losses of the uranium of $0.1 \%$, which ends up in the waste stream.

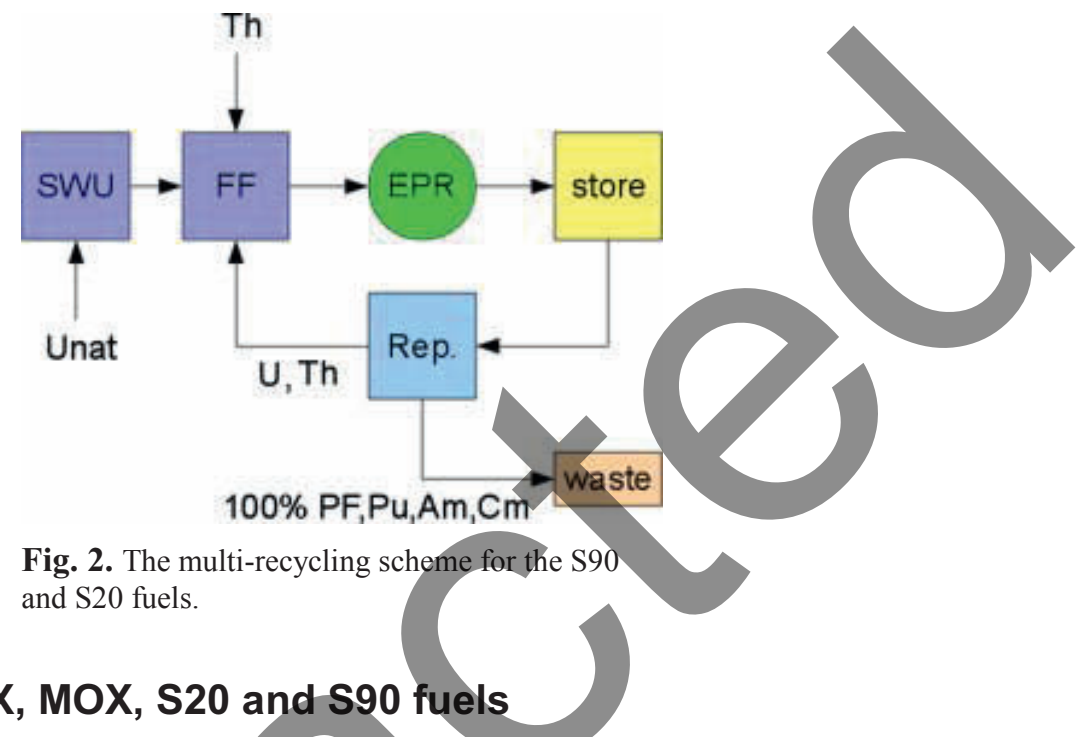

\section{Evolution of UOX, MOX, S20 and S90 fuels}

There is a substantially higher fissile concentration $\left({ }^{233} \mathrm{U}\right.$ and $\left.{ }^{235} \mathrm{U}\right)$ in the uranium vector from the S90 fuel than the S20 fuel, where the majority of the uranium is ${ }^{238} \mathrm{U}$. The initial and final inventories of ${ }^{235} \mathrm{U}$ are very similar for all three cases; however, for UOX, the remaining fissile ${ }^{235} \mathrm{U}$ is not re-used in any significant quantities in current reactors since it requires re-enrichment. This would not be the case for the S90 and S20 fuels where the goal is to exploit the energy contained in the fissile uranium isotopes by multi-recycling the fuel.

The major long-lived waste production processes in the S90 and S20 fuels are the ${ }^{235} \mathrm{U}(\mathrm{n}, \gamma) \rightarrow$ ${ }^{236} \mathrm{U}(\mathrm{n}, \gamma) \rightarrow{ }^{237} \mathrm{U}(\beta-) \rightarrow{ }^{237} \mathrm{~Np}\left(2.1 \times 10^{6} \mathrm{y}\right)$ and ${ }^{232} \mathrm{Th}(\mathrm{n}, 2 \mathrm{n}) \rightarrow{ }^{231} \mathrm{Th}(\beta-) \rightarrow{ }^{231} \mathrm{~Pa}\left(3.3 \times 10^{4} \mathrm{y}\right)$. The plutonium from the S20 fuel differs little in composition to that from the UOX so it could easily be recovered and used to fabricate MOX fuel to gain an extra $5.2 \%$ of energy for the same initial quantity of natural uranium used. However, the plutonium produced in the S90 fuel is probably not suitable for re-use due to the low fissile content (only $37 \%)$ and the very high content of ${ }^{238} \mathrm{Pu}(47 \%)$ produced from three successive captures on ${ }^{235} \mathrm{U}$ which would render it extremely active. The

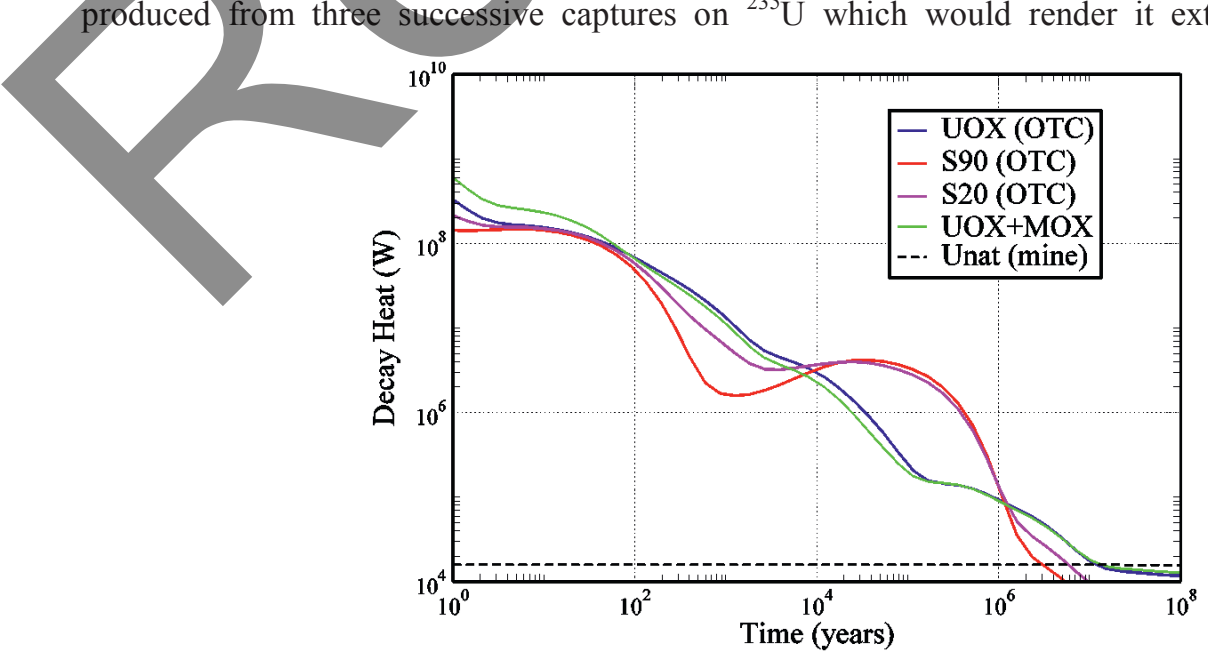

Fig. 3. Decay heat of the waste streams from the different fuel types for spent fuel in open cycle from a full EPR core 
quantities of plutonium, americium and curium produced with the S90 and S20 fuel are roughly factors of around 15 and 3 less respectively.

\subsection{Once through cycle}

Figure 3 shows the decay heat for the UOX, S20 and S90 fuels in open cycle from the entire EPR core. The thoriated fuels gain at $10^{3}$ years, due to the low rates of production of plutonium, americium and curium isotopes, but lose over periods around $10^{5}$ years due to the un-recovered uranium (mainly the ${ }^{233} \mathrm{U}$ and ${ }^{234} \mathrm{U}$ isotopes at this time scale). The conclusion is that without multirecycling there is little to be gained from using thoriated fuels.

\subsection{Recycling the uranium}

Figure 4 shows the evolution of the S90 fuel uranium vector composition during three irradiation cycles of $65 \mathrm{GWd} / \mathrm{t}$. New enriched uranium $(90 \%$ in this case) is added at each reloading to

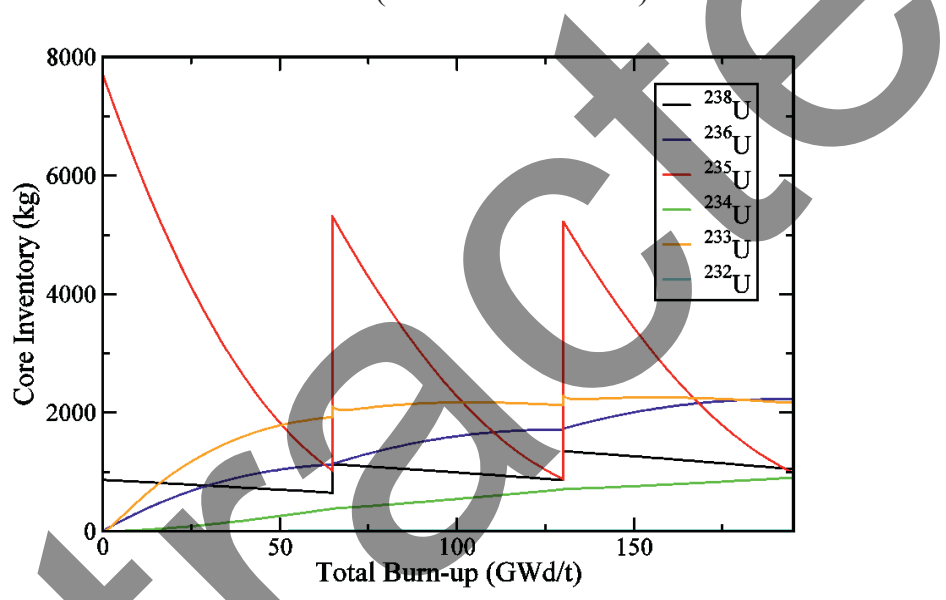

Fig. 4. Evolution of the uranium vector for the $S 90$ fuel over three complete cycles with discharge burn-ups of $65 \mathrm{GW} / \mathrm{t}$.

The small additional amount of ${ }^{233} \mathrm{U}$ available after each cycle

comes from the decay of ${ }^{233} \mathrm{~Pa}$.

compensate for the loss of fissile material during the irradiation. The core inventory of ${ }^{233} \mathrm{U}$ is seen to stabilize very quickly at around $2200 \mathrm{~kg}$. However, the non-fissile uranium isotopes continue to

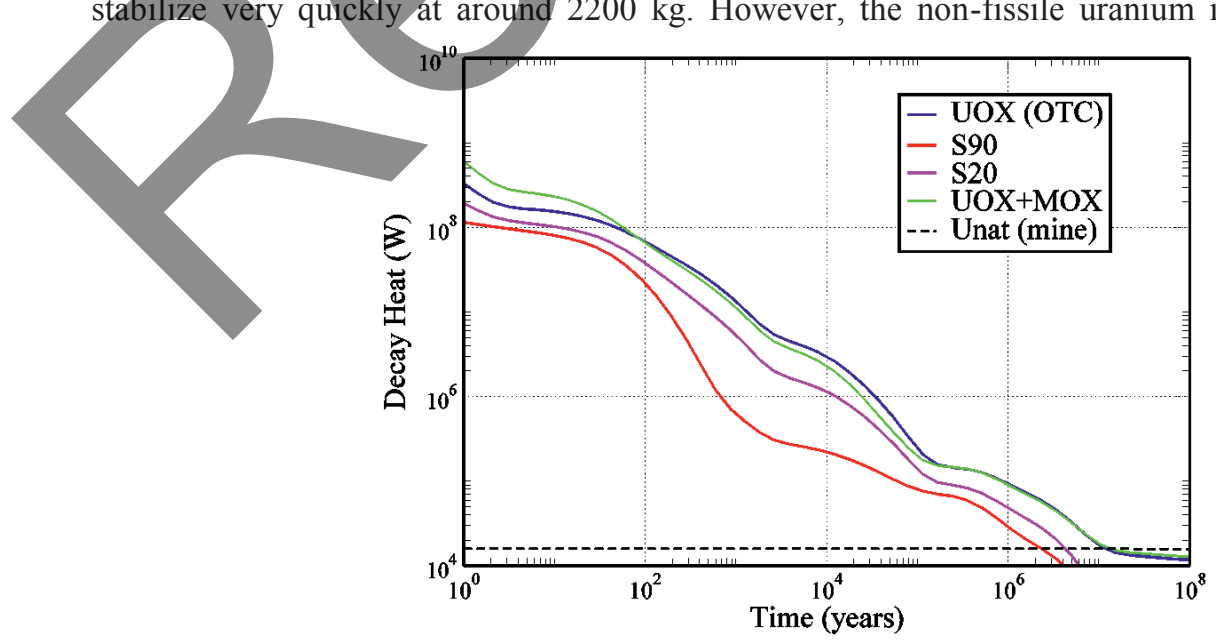

Fig. 5. Decay heat of the waste streams from the different fuel types for spent fuel from a full EPR core after the first irradiation of $65 \mathrm{GWd} / \mathrm{t}$. Uranium is recycled in the thorium fuel cases 
accumulate with each cycle and the uranium vector does not reach equilibrium until after around seven or eight cycles. The same is true for the S20 fuel, and thus the fuel performance of the thoriated fuels degrades slightly with each re-cycle in two ways: (1) slightly more enriched uranium needs to be added at each reloading to compensate for the absorption of neutrons on the non-fissile uranium isotopes and (2) the inventory of TRU's at discharge will increase slightly after each recycle. The total amount of uranium needed at each re-loading is thus approximately half of that which was required at the initial loading thus economizing significantly on natural uranium needs for the rest of the life of the reactor if the multi-recycling is continued.

If uranium recycling is performed then the decay heat and radio-toxicities of the S20 and S90 spent fuels will be much lower (see Figure 5), since the uranium is kept in the cycle and does not enter the waste stream, except for small reprocessing losses of $0.1 \%$. After 1000 years the radiotoxicity and the decay heat production for the S90 fuel is approximately 20 times less than the UOX - a very large reduction. The gain for the S20 fuel is not as dramatic, but still lead to a significant reduction in radio-toxicity and decay heat after 1000 years (by a factor of $\sim 3$ ). The UOX + MOX curve shows the combined decay heat of the UOX fuel without the plutonium and the resulting MOX spent fuel. This mono-recycling option, which is in widespread use in Europe and Japan, offers a 30\% reduction in waste radio-toxicity and decay heat as compared to OTC, after 1000 years and provides an additional $13.7 \%$ more energy at the long burn-ups of $65 \mathrm{GWd} / \mathrm{t}$ studied here.

\subsection{Proliferation}

The current internationally accepted enrichment limit for uranium is $20 \%$, so it would be possible to use the S20 fuel in a commercial power rector such as the EPR. However, the S90 fuel would probably be ruled out due to proliferation concerns. Nevertheless, the S90 fuel could be presented as a means of rendering safe weapons grade uranium from decommissioned nuclear warheads in a similar manner to the Megatons-to-Megawatts ${ }^{\mathrm{TM}}$ program.

However, the thoriated fuels do have one major anti-proliferation advantage in that the spent fuels at discharge are exceptionally proliferation resistant. It is practically impossible to manufacture a ${ }^{233} \mathrm{U}$-based weapon in the presence of ${ }^{232} \mathrm{U}$ contamination. Illegal transportation of recycled uranium would also be more difficult, and be very easy to discover due to the penetrating 2.6 $\mathrm{MeV}$ gamma rays.

\subsection{Safety}

The thoriated fuels differ from the UOX and MOX fuels in safety aspects in some important ways: The delayed neutron fraction of ${ }^{233} \mathrm{U}$, is lower than ${ }^{235} \mathrm{U}$ and similar to that of ${ }^{239} \mathrm{Pu}$ and hence calculations show that the beta effective value for an EPR assembly drops over the cycle from around $700 \mathrm{pcm}$ at beginning of cycle (BOC), for all fuels except MOX, to values of $493 \mathrm{pcm}, 449$ $\mathrm{pcm}, 422 \mathrm{pcm}$ and $429 \mathrm{pcm}$ for UOX, S20, S90 and MOX fuels respectively. Since the EPR core is designed to be fully loaded with MOX fuel the lower delayed neutron fractions of S20 and S90 fuels should not present a problem. Furthermore, there are the ${ }^{233} \mathrm{~Pa}$ reactivity effects, caused by the relatively long half-life of ${ }^{233} \mathrm{~Pa}$ (27 days), compared to the UOX cycle with ${ }^{239} \mathrm{~Np}$ ( 2.4 days). The inventory of ${ }^{233} \mathrm{~Pa}$ will therefore be considerably larger and can present a problem at reactor shutdown since new fissile material will continue to accumulate and the reactivity will increase. Core ${ }^{233} \mathrm{~Pa}$ inventories at shutdown for S90 and S20 fuels are $155 \mathrm{~kg}$ and $102 \mathrm{~kg}$ respectively, compared to around $4.6 \mathrm{~kg}$ of ${ }^{239} \mathrm{~Np}$ for UOX fuel. MURE simulations show that this reactivity increase corresponds to approximately $10 \%$ of the total control rod worth of the EPR, so there is a

\footnotetext{
${ }^{\mathrm{b}}$ The Megatons-to-Megawatts ${ }^{\mathrm{TM}}$ program is a US government-industry partnership in which bomb-grade uranium from dismantled Russian warheads is being recycled into LEU used to produce fuel for American nuclear power plants.
} 
sufficiently large shutdown safety margin to compensate for the ${ }^{233} \mathrm{~Pa}$ effect. The ${ }^{135} \mathrm{Xe}$ and ${ }^{149} \mathrm{Sm}$ poisoning effects are similar to UOX fuel, so no additional problem would appear. Fuel temperature coefficients (Doppler) are similar for all fuels at typically $-3.5 \mathrm{pcm} / \mathrm{K}$. Void coefficients of reactivity for the proposed fuels have also been simulated and are found to be $\Delta \rho$ : $-0.660,-0.737$ and -0.668 at BOC and $\Delta \rho:-0.438,-0.526$ and -0.457 at EOC for UOX, S90 and S20 fuels respectively. Therefore, the ${ }^{232} \mathrm{Th}$ content of these fuels has the extra beneficial effect of increasing void safety margins.

\subsection{Economics}

Commercial reactors are operating with recycled plutonium in Western Europe, but uranium is not being recycled significantly because of the currently low cost of fresh uranium. With the thoriated fuels uranium recycling is an absolute necessity for economic viability. For the initial loading of the EPR with the S20 and S90 fuels, approximately 35\% more SWUs and slightly more natural uranium is needed. However, once thoriated fuel multi-recycling is performed this initial investment is repaid by the recovery of significant quantities of fissile ${ }^{233} \mathrm{U}$ and ${ }^{235} \mathrm{U}$, and for the remainder of the reactor's life the SWU and natural uranium needs will be reduced by factors of approximately $25 \%$ and $45 \%$ respectively when compared to standard UOX fuel.

\section{Conclusions}

Thorium can be used as the fertile material in EPR fuels if there is an extra supply of neutrons - in this case uranium of between $20 \%$ and $90 \%$ enrichment. The thorium fuel cycle in the EPR could be one method of creating a more sustainable nuclear power leading to a significant economy of uranium resources and large reduction in volumes of long-lived radioactive waste produced. However, the thoriated fuels require multi-recycling of the uranium to recover the useful fissile material $\left({ }^{233} \mathrm{U}\right.$ and $\left.{ }^{235} \mathrm{U}\right)$, which requires specially adapted reprocessing technology. Nevertheless, this is a realistic, potentially economically viable option that does not dependent on huge leaps in technological progress and/or the successful demonstration/construction of radically innovative reactor designs, and could therefore be implemented rapidly if desired.

\section{References}

1. J.C. Clayton, The Shippingport Pressurized Water Reactor and Light Water Breeder Reactor. Technical Report (1993)

2. L. Mathieu, et al., Nuclear Energy 48, pp. 664-679 (2006) J. Brizi, et al, Proceedings of Global 2009 International Conference GLOBAL 2009. The Nuclear Fuel Cycle: Sustainable Options and Industrial Perspectives (Paris, France, 2009)

4. C. Rubbia, et al., Conceptual Design of a Fast Neutron Operated High Power Energy Amplifier, European Organization for Nuclear Research, Geneva (1995)

5. S. David, et al. Nuclear Instrumentation and Methods in Physics Research A, 443 pp. 510-530 (2000)

6. Adonai Herrera-Martinez, Yacine Kadi, Geoffrey Parks, Marcus Dahlfors, Annals of Nuclear Energy 34, pp. 564-578 (2007)

7. T.E. Booth, F.B. Brown, J.S. Bull, et al., MCNP5 1.50 Release Notes. LA-UR-08-2300, Los Alamos National Laboratory Report (2005).

8. O. Méplan, et al., ENC Proceedings (Versailles, France, 11-14 December, 2005) 